\title{
Influence of thermal treatment duration on structure and phase composition of additive Co-Cr-Mo alloy samples
}

\author{
M. A. Khimich ${ }^{\dagger, 1,2}$, E. A. Ibragimov ${ }^{3}$, A. I. Tolmachev ${ }^{1}$, V. V. Chebodaeva ${ }^{1}$, P. V. Uvarkin ${ }^{1}$, \\ N. A. Saprykina ${ }^{3}$, A. A. Saprykin ${ }^{3}$, Yu. P. Sharkeev ${ }^{1,3}$ \\ †khimich@ispms.tsc.ru \\ ${ }^{1}$ Institute of Strength Physics and Materials Science Siberian Branch of the RAS, Tomsk, 634055, Russia \\ ${ }^{2}$ National Research Tomsk State University, Tomsk, 634050, Russia \\ ${ }^{3}$ National Research Tomsk Polytechnic University, Tomsk, 634050, Russia
}

Laser powder bed fusion (LPBF) requires application of powders with specific characteristics. These are near-spherical shape of particles, uniform elemental composition, typical particle size of $5-70 \mu \mathrm{m}$, etc. Such powders are produced by spheroidization methods. They have such disadvantages as high cost and sale only in large quantities. There are publications describing application in LPBF powders, produced by the methods, alternative to spheroidization. In the current study, powders of pure raw $\mathrm{Co}, \mathrm{Cr}$ and Mo were used for the production of Co-Cr-Mo powder mixture. Samples of Co- $28 \mathrm{wt} . \% \mathrm{Cr}-6 \mathrm{wt} . \% \mathrm{Mo}$ alloy were produced by LPBF from this powder mixture. Due to the difference between melting temperatures of $\mathrm{Co}, \mathrm{Cr}$ and $\mathrm{Mo}$, inclusions of $\mathrm{Cr}$ and Mo were formed within the bulk of samples. Studies of phase and elemental composition, structure and microhardness of the as-produced samples and after post-treatment with varied duration are represented. As-produced samples have non-uniform elemental composition and are represented by the main Co-based phase. Increasing the annealing duration leads to the sequential dissolution of un-melted $\mathrm{Cr}$ and Mo inclusions. Complete dissolution of $\mathrm{Cr}$ particles was observed at 10 hours of treatment and complete dissolution of Mo particles was not observed after 20 hours of annealing. Microhardness non-linearly changes with the increasing duration of annealing. This is due to the phase transformations and diffusion processes occurring at such type of post-treatment. Complete dissolution of Mo-particles could be achieved by further increasing the annealing time or by varying the mode of laser powder bed fusion.

\section{Влияние продолжительности термической обработки на структуру и фазовый состав образцов сплава Co-Cr-Mo, полученных с помощью аддитивных технологий}

\author{
Химич М. А. ${ }^{\dagger, 1}$, , Ибрагимов Е. А. ${ }^{3}$, Толмачев А. И. ${ }^{1}$, Чебодаева В. В. ${ }^{1}$, Уваркин П. В. ${ }^{1}$, \\ Сапрыкина Н. А. ${ }^{3}$, Сапрыкин А. А. ${ }^{3}$, Шаркеев Ю. П., \\ ${ }^{1}$ Институт физики прочности и материаловедения Сибирского отделения РАН, Томск, 634055, Россия \\ ${ }^{2}$ Национальный исследовательский Томский государственный университет, Томск, 634050, Россия \\ ${ }^{3}$ Национальный исследовательский Томский политехнический университет, Томск, 634050, Россия
}

Селективное лазерное сплавление (СЛС) требует применения порошков с особыми характеристиками. Этими характеристиками являются форма частиц, близкая к сферической, однородный элементный состав, типичный размер частиц 5-70 мкм и т. д. Такие порошки получают методами сфероидизации. У них есть такие недостатки, как высокая стоимость и продажа только в больших количествах. Имеются публикации, описывающие применение при СЛС порошков, полученных методами, альтернативными сфероидизации. В настоящем исследовании для производства порошковой смеси Со-Сr-Мо использовались порошки чистого исходного Сo, $\mathrm{Cr}$ и Мо. Образцы сплава Со-28 мас.\% Сr-6мас.\% Мо были изготовлены методом СЛС из этой порошковой смеси. Из-за разницы температур плавления $\mathrm{Co}, \mathrm{Cr}$ и Мо в объеме образцов образовались включения $\mathrm{Cr}$ и Мо. Представлены исследования фазового и элементного состава, структуры и микротвердости образцов в исходном состоянии и после постобработки различной продолжительности. Полученные образцы имеют неоднородный элементный состав и представлены 
основной фазой на основе Со. Увеличение продолжительности отжига приводит к последовательному растворению нерасплавленных включений Cr и Мо. Полное растворение частиц Cr наблюдалось через 10 часов обработки, а полное растворение частиц Мо через 20 часов отжига не наблюдалось. Микротвердость изменяется нелинейно с увеличением продолжительности отжига. Это связано с фазовыми превращениями и диффузионными процессами, происходящими при таком виде пост-обработки. Полное растворение Мо-частиц может быть достигнуто при еще большем увеличении продолжительности отжига или при изменении режима ЛНП.

Ключевые слова: селективное лазерное сплавление, исходные элементные порошки, сплавы Сo-Сr-Мо, термическая обработка, структура, фазовый состав.

\section{Introduction}

Laser powder bed fusion (LPBF) is a method of additive manufacturing (AM), which allows the formation of products with a unique structure, composition and properties. LPBF requires special powder as the initial material. Commercial LPBF-installations use mainly certain pre-alloyed powders with particles $10-70 \mu \mathrm{m}$ in size, having a near-spherical shape and pre-set phase and chemical composition [1]. These powders could be produced by such methods as centrifugal gas atomization, plasma spraying $[2,3]$, etc. Due to the rapid crystallization, methods of spheroidization provide flowable powders with near-spherical particles of the required size, phase and elemental composition. However, spheroidization methods have such disadvantages as high cost and the need for special equipment.

In the technology of gas atomization, there is a problem of oxide inclusions and impurity particles [4-6]. As described in [7], "the differences in solidification time give the opportunity for the particles to stick together". The plasma rotating electrode process has low efficiency, a yield of fine powders and a high cost $[8,9]$. The same is true for plasma atomization and spheroidization methods. Both have the problem of material evaporation, which significantly increases the cost of the final powder, i. e. the cost of the LPBF product also increases.

Another problem of these methods is the amount of powder. All these methods allow forming a near-spherical powder, but they require amounts of initial material estimated in kilograms and provide kilograms of final powder. But for scientific purposes it is not required to acquire that much.

Therefore, there are studies devoted to methods alternative to spheroidization. These methods provide the results of less quality, but the powder itself is significantly cheaper, could be produced in comparatively small amounts and could be used in custom-made installations, which is very important for researchers developing new modes and parameters of LPBF.

Mechanical alloying allows the formation of powders that meet most of the LPBF requirements $[10,11]$. Also, there were attempts to use powder mixtures, produced by sieving or ultrasonic treatment [12].

The use of powders produced by mechanical alloying or sieving prompts the formation of non-uniform elemental distribution throughout the bulk of the product and can lead to the formation of non-desirable properties $[12,13]$. Such a result is possible in the case of powders having rather different melting temperatures [14]. In [14], the authors describe the formation of Ti-Al-Nb alloys of different compositions by selective laser melting (SLM). I. Polozov et al. observed the formation of not completely melted $\mathrm{Nb}$ particles. The authors propose to apply thermal treatment $[14,15]$, which is typical for AM. Annealing allows reducing the level of residual stresses and eliminating the inhomogeneity of the elemental composition. It was shown that annealing of $\mathrm{Ti}-\mathrm{Al}-\mathrm{Nb}$ SLM-samples at $1200^{\circ} \mathrm{C}$ leads to complete dissolution of $\mathrm{Nb}$ particles into the Ti-Al matrix [16].

An increase in the duration of post-treatment leads to an acceleration of the dissolution process [17]. The interdiffusion coefficients depend on the temperature and concentrations of the compounds [18]. In case of LPBF, the concentration is constant throughout the bulk of the sample, but with the onset of interdiffusion, it will be gradually changed in local regions of the sample. The temperature in this case is a variable parameter and should be chosen according to the experimental and published data.

The authors of [19] studied the influence of complex heat-treatment (up to $1200^{\circ} \mathrm{C}$ ) on the microstructure in SLM-samples of the Co-29 wt.\% Cr-6 wt.\% Mo alloy. In [20], the samples were annealed during 2 hours at $1200^{\circ} \mathrm{C}$ with the aim of relaxation of the residual stresses. Annealing at $1150^{\circ} \mathrm{C}$ allowed forming a single-phase fcc-solid solution in Co-Cr-Mo samples produced by sintering of a near-spherical powder [21]. Other methods of thermal-post-treatment of Co-Cr-Mo alloys produced by AM are described in [22-26]. However, there are no data describing LPBFsamples of Co-Cr-Mo alloys produced from the raw $\mathrm{Co}, \mathrm{Cr}$ and Mo powders and the influence of thermal treatment on characteristics of those samples. We propose a new way of formation of LPBF-samples starting from the preparation of the initial powder. Our method of mechanical mixing of raw-powders of $\mathrm{Co}, \mathrm{Cr}$ and Mo by multiple sieving allows reducing the cost of the applied powder material and of the entire process. However, the use of this powder leads to nonhomogeneity of the elemental composition in the produced samples. The aim of work was to estimate the influence of the duration of post-treatment on the structure, elemental and phase composition of Co-Cr-Mo alloy samples formed by LPBF.

\section{Methodology}

Powders of commercially pure $\mathrm{Co}, \mathrm{Cr}$ and Mo were used as the initial raw powder material. The Co powder was represented by single-phased conglomerates of irregular shape and within the size range of $10-150 \mu \mathrm{m}$ [27]. The size of single-phased irregular-shaped $\mathrm{Cr}$ particles did not exceed $250 \mu \mathrm{m}$, and the single-phased Mo powder consisted of irregular-shaped conglomerates within the size range of $10-150 \mu \mathrm{m}$ [27]. They were used for the production of a powder mixture containing $66 \mathrm{wt} . \% \mathrm{Co}, 28 \mathrm{wt} . \% \mathrm{Cr}$ and 
6 wt.\% Mo. The mixture was produced by long-term multiple sieving. Sieving was carried out on automatic mesh sieve. The obtained powder mixture was LPBF-treated on a custommade "VARISKAF-100MVS" installation [13]. The applied LPBF mode was following: the laser beam power $-100 \mathrm{~W}$, the modulation frequency in the pulse-periodic mode $5 \mathrm{kHz}$, the scanning velocity $-350 \mathrm{~mm} / \mathrm{s}$, the thickness of the powder layer $-30 \mu \mathrm{m}$, the hatch space $-100 \mu \mathrm{m}$. The samples were formed in the shape of parallelepipeds with a square at the base with a side of $10 \mathrm{~mm}$. The height of the samples was $5.0 \pm 0.1 \mathrm{~mm}$. The bulk porosity of the obtained samples was $12 \pm 3 \%$.

All the samples were washed in an ultrasonic bath in distilled water, grinded, polished and washed again in distilled water and ethyl alcohol. Etching was carried out in an $\mathrm{HCl}: \mathrm{H}_{2} \mathrm{O}_{2}$ solution with a components ratio of $5: 1$ [28], respectively and in a solution of $\mathrm{HNO}_{3}: \mathrm{HCl}$ with a ratio of 1:3 [19]. After etching, the samples were washed. Annealing post-treatment was carried out in high vacuum at $1050^{\circ} \mathrm{C}$. Heating was carried out at a rate of $500^{\circ} \mathrm{C} / \mathrm{h}$. The duration of annealing was $4,6,8,10,12,14$ and 20 hours. Then furnace cooling was applied.

The phase composition was characterized by X-ray diffraction analysis (XRD) on a DRON-7 X-ray diffratometer (Bourevestnik, St. Petersburg, Russia) in $\mathrm{CoK}_{\alpha}$-radiation. $2 \theta$ angle range was $30-100^{\circ}$ with a scanning step of $0.05^{\circ}$ and acquisition time of $5 \mathrm{~s}$. The microstructure and elemental composition were studied on Zeiss Leo Evo 50 (Zeiss, München, Germany) and Quanta 200 3D (FEI Company, Hillsboro, USA) scanning electron microscopes, equipped with an energy dispersive spectroscopy accessory (EDS) and detectors of secondary electrons (SE) and back-scattered electrons (BSE). Microhardness was measured using Duramin-5 (Struers, Ballerup, Denmark). The measurements were performed according to the Vickers method with a load of $100 \mathrm{~g}$. The distance between the indentations was $500 \mu \mathrm{m}$. All the studies were carried out at "Nanotech" Common Use Center and Tomsk Material Science Common Use Center.

\section{Results and Discussion}

As described in [29], the microstructure of the as-produced samples was represented by dendrites with a space between them less than $2 \mu \mathrm{m}$ (Fig. 1a). This is due to the rapid cooling. Such a structure could lead to anisotropy of the mechanical properties of products [30]. Inclusions of un-melted $\mathrm{Cr}$ and Mo particles were observed in the bulk of the samples
(Fig. 1b). The presence of inclusions is connected with a large difference between the melting temperatures of Co, $\mathrm{Cr}$ and Mo. Energy input during LPBF was insufficient for complete dissolution of $\mathrm{Cr}$ and Mo. The phase composition was represented by 87 vol. $\%$ of the main $\varepsilon$-phase and 13 vol.\% of the $\gamma$-phase. The lattice parameters of both phases did not correspond to the etalon. This was due to the formation of solid solutions on the basis of two possible Co lattices, corresponding to high-and low-temperature $\varepsilon$ - and $\gamma$-phases $[29,31]$. It should be noted, that here and further $\varepsilon, \gamma, \sigma$ and $\mu$ symbols are used to define the type of lattice, which are hcp, fcc, tetragonal and rhombohedral, respectively. Each symbol is not attached to a certain chemical composition and could describe more than one phase [32-34]; therefore, the compositions of the described phases are explained after each mention.

Annealing at $1050^{\circ} \mathrm{C}$ for 4 hours led to the onset of diffusion. The boundaries of $\mathrm{Cr}$ and Mo inclusions became blurred. EDS showed a change in the concentration of Co, $\mathrm{Cr}$ and Mo within the areas corresponding to the inclusions. The Cr concentration reached 96 wt.\% in the center of dark inclusions and about 9 wt.\% at the blurred boundaries, and Mo concentration was 98 wt.\% in the center of light inclusions and about 2 wt.\% at the blurred boundaries. The phase composition corresponded to 61 vol. $\%$ of the $\sigma$-phase, 18 vol. $\%$ of $\mathrm{Co}_{0.62} \mathrm{Cr}_{0.38}$ and 21 vol.\% of $\mathrm{Co}_{0.8} \mathrm{Mo}_{0.2}$. It should be noted that the $\sigma$-phase is the substitutional solid solution, where inside the Co-matrix could be dissolved $\mathrm{Cr}$ [35] or Mo [18]. In the case of $\mathrm{Cr}$, the $\sigma$-phase is represented by $\mathrm{Co}_{0.4} \mathrm{Cr}_{0.6}$ and in the case of $\mathrm{Mo}$ it is represented by $\mathrm{Co}_{2} \mathrm{Mo}_{3}$. In our case, according to the calculated lattice parameters, the $\sigma$-phase was represented by $\mathrm{Co}_{0.4} \mathrm{Cr}_{0.6}$.

An increase in the annealing time up to 6 hours led to a greater broadening of the diffusion areas of the inclusions and blurring of the boundaries of the diffusion areas. Areas with Mo concentration below 43 wt.\% and $\mathrm{Cr}$ concentration below 44 wt.\% were observed, i.e. increasing the annealing time leads to gradual dissolution of $\mathrm{Cr}$ and Mo particles within the Co-matrix. It should be noted that the number of dark areas in BSE-images after 6 hours was significantly lower than that after 4 hours of treatment. In the case of light areas corresponding to Mo inclusions, such phenomenon was not observed. This is due to the fact that $\mathrm{Cr}$ has the melting temperature lower than $\mathrm{Mo}$, which are $1907^{\circ} \mathrm{C}$ [36] and $2623^{\circ} \mathrm{C}$ [37], respectively, i.e. the complete dissolution of $\mathrm{Cr}$ particles requires less time of post-treatment. Phase composition after 6 hours of annealing was represented by

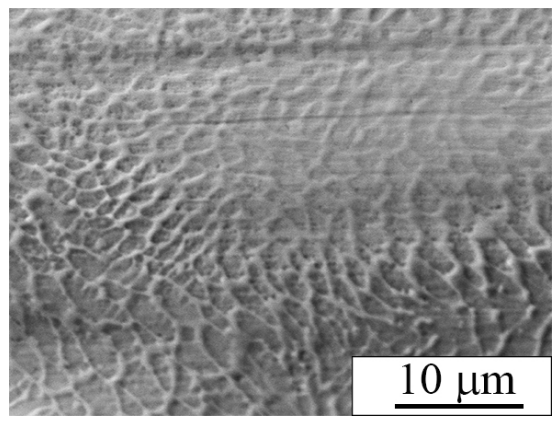

a

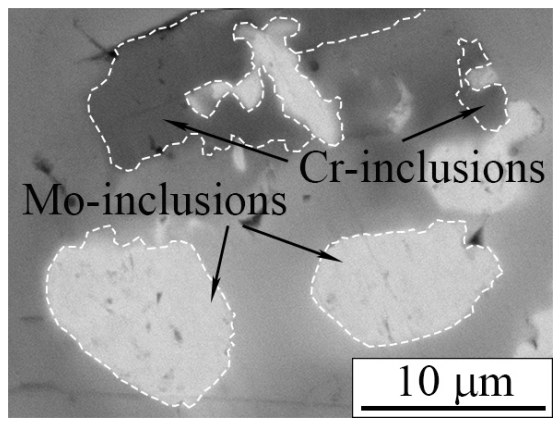

b

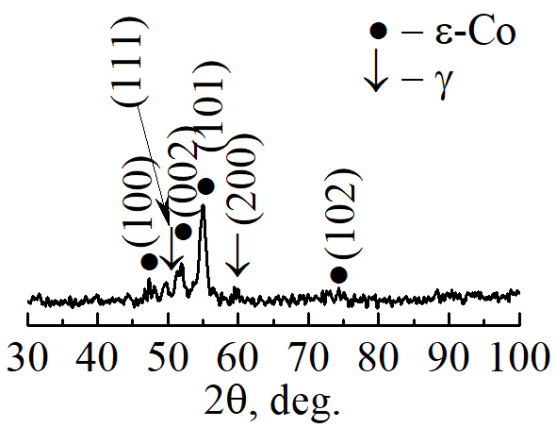

c

Fig. 1. SE (a) and BSE (b) SEM-images and XRD-pattern (c) of the as-produced LPBF sample after etching. 
27 vol.\% of the $\sigma$-phase $\left(\mathrm{Co}_{0.4} \mathrm{Cr}_{0.6}\right), 52$ vol.\% of $\mathrm{Co}_{0.62} \mathrm{Cr}_{0.38}$ and $21 \mathrm{vol} . \%$ of $\mathrm{Co}_{0.8} \mathrm{Mo}_{0.2}$. Such a decrease in the volume fraction of the $\sigma$-phase was due to the ongoing process of diffusion and phase transformation, which in turn, was a sequence of redistribution of $\mathrm{Co}, \mathrm{Cr}$ and Mo over the bulk of the samples.

An 8-hours annealing reduced the number of $\mathrm{Cr}$ inclusions more significantly than a 6-hours one. EDS in local areas showed dark inclusions with a $\mathrm{Cr}$ concentration not exceeding 46 wt.\% and light inclusions with a Mo concentration not exceeding $35 \mathrm{wt} . \%$. The boundaries of the diffusion areas became more blurred and the size of these areas increased significantly. The phase composition was represented by 58 vol. $\%$ of $\varepsilon$ - and 42 vol. $\%$ of $\mu$-phases. In this case, the $\varepsilon$-phase was represented by $\mathrm{Co}_{0.62} \mathrm{Cr}_{0.38}$ and the $\mu$-phase - by intermetallic $\mathrm{Co}_{7} \mathrm{Mo}_{6}$. It is obvious that the amount of $\mathrm{Co}_{0.62} \mathrm{Cr}_{0.38}$ is increased with increasing the duration of annealing. At the same time, other phases observed after 4 and 6 hours of annealing, have not been identified, which proves that the process of phase transformation continues.

Post-treatment for 10 hours led to the complete dissolution of Cr-inclusions. EDS showed a uniform distribution of $\mathrm{Cr}$ over the bulk of the samples and its concentration did not exceed 30 wt.\%. Mo-inclusions were still observed (Fig. 2 a). Some of the Mo particles dissolved (Fig. 2 a), which led to the formation of large areas with an increased Mo concentration (up to $20 \mathrm{wt} . \%$ ). Annealing for 10 hours led to increasing the size of diffusion areas over Mo-inclusions. Some of those areas were consolidated (Fig. 2 a). The concentration of Mo did not exceed $30 \mathrm{wt} . \%$ in the inclusions. The phase composition was represented by 50 vol. $\%$ of $\mathrm{Co}_{0.62} \mathrm{Cr}_{0.38}, 17$ vol.\% of $\mu$-phase $\left(\mathrm{Co}_{7} \mathrm{Mo}_{6}\right)$ and 33 vol.\% of $\sigma$-phase $\left(\mathrm{Co}_{0.4} \mathrm{Cr}_{0.6}\right)$. It should be noted, that after 8 hours of annealing, the $\sigma$-phase was not observed. It is known that thermal treatment leads to the $\varepsilon \rightarrow \varepsilon+\sigma$ phase transformation [35]. The formation of the $\mu$-phase is connected with the decay of the $\varepsilon$-phase and transformations of $\sigma$ - and $\varepsilon$-phases [38]. Thus, a 10-hours annealing at $1050^{\circ} \mathrm{C}$ leads to partial $\varepsilon \rightarrow \varepsilon+\mu+\sigma$ and $\mu \rightarrow \sigma$ transformations, which agrees with the data in $[25,39]$.

The number of Mo-inclusions decreased even more after 12 hours of annealing. The Mo concentration did not exceed 30 wt.\%. All the boundaries between Mo diffusion areas were broadened, blurred and consolidated, but there were diffusion areas detached from others. The concentration of $\mathrm{Cr}$ did not exceed 29 wt.\%. The phase composition was represented by the same phases as after 10 hours of annealing. The volume fraction of the $\varepsilon$-phase was $28 \%$, the $\mu$-phase $-38 \%$ and the $\sigma$-phase $-34 \%$.

Annealing for 14 hours led to the consolidation of all Mo diffusion areas. The Mo-concentration at local points did not exceed $25 \mathrm{wt} . \%$. The minimum concentration of Mo in some areas was 6 wt.\%. Post-treatment for 14 hours led to a phase transformation. The phase composition was represented by 67 vol.\% of $\varepsilon$-phase $\left(\mathrm{Co}_{0.62} \mathrm{Cr}_{0.38}\right)$ and 33 vol.\% of $\sigma$-phase $\left(\mathrm{Co}_{0.4} \mathrm{Cr}_{0.6}\right)$. A 14-hours annealing led to the total decay of the intermetallic $\mu$-phase [40].

A 20-hours annealing did not lead to complete dissolution of Mo inclusions (Fig. $3 \mathrm{a}$ ). Mo diffusion areas were distributed over the entire bulk of the samples; however, the Mo concentration varied in local regions of the samples. In local areas, the concentration of Co was 64 wt.\%, of $\mathrm{Cr}-$ 29 wt.\% and of Mo - 6 wt.\%. An increase in the annealing time led to an increase in the volume fraction of the $\varepsilon$-phase up to $85 \%$ and a decrease in the volume fraction of the $\sigma$-phase to $15 \%$. Since Mo-inclusions were not completely

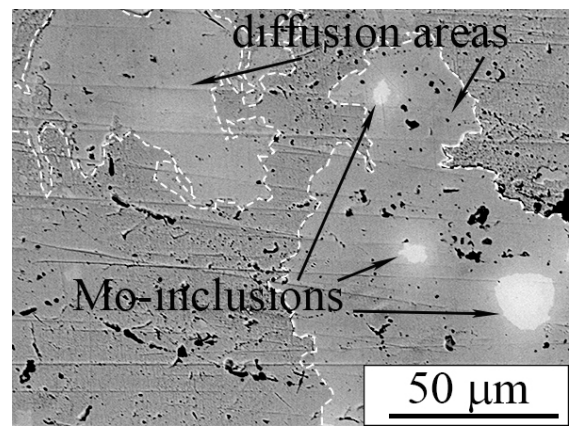

$\mathrm{a}$

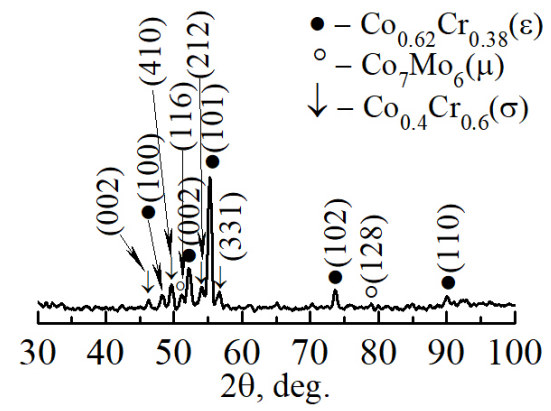

b

Fig. 2. BSE (a) SEM-image and XRD-pattern (b) of the etched LPBF sample after 10 hours of annealing.

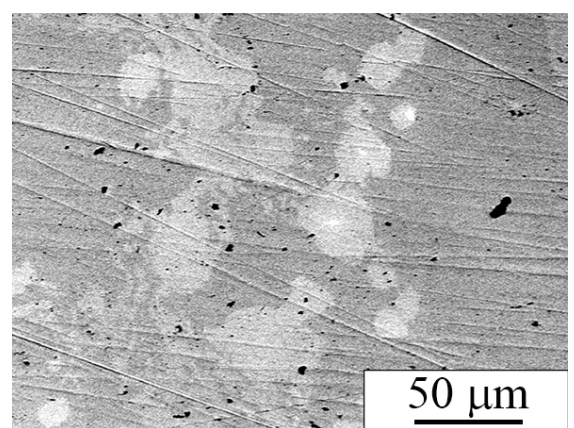

a

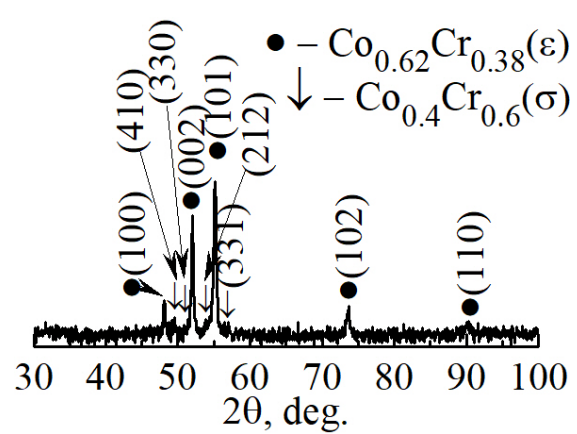

b

Fig. 3. BSE (a) SEM-image and XRD-pattern (b) of the etched LPBF sample after 20 hours of annealing. 


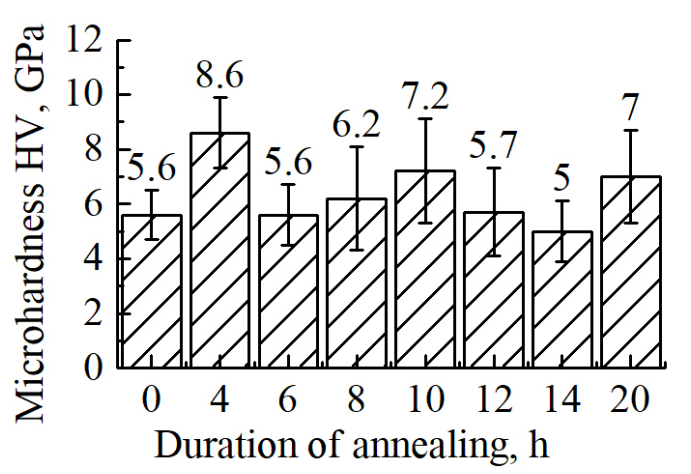

Fig. 4. Microhardness of Co-Cr-Mo LPBF-samples according to the duration of annealing.

dissolved after 20 hours of annealing, we concluded, that this result could be achieved by varying the LPBF mode at the stage of production of the samples. For example, the power of laser beam could be increased, additional re-melting of the formed layer could be introduced into the process or a scanning strategy of overlapping the hatch spaces could be applied.

The microhardness of all the samples was measured. The measurements results are represented in Fig. 4. It should be noted that the size of each Vickers indentation was about $500 \mu \mathrm{m}$, therefore the results of microhardness measurements are an integral characteristic of the studied bulk of each sample rather than each certain phase. The as-produced samples were characterized by a lower value of microhardness in comparison to the post-treated samples. The highest value was achieved in the samples annealed for 4 hours. This is due to the onset of diffusion and phase transformations. The volume fraction of the $\sigma$-phase in the samples annealed for 4 hours was $61 \%$, which is the highest value among all the studied samples. Annealing for 6 hours led to a decrease in the microhardness to the same value as in the as-produced samples. This could be caused by decreasing the amount of the $\sigma$-phase. 8 and 10 hours of annealing lead to an increase in the microhardness value, which could be due to the appearance and subsequent increase in the amount of $\sigma$ - and $\mu$-phases. The subsequent decrease in microhardness at 12 and 14 hours of annealing is due to the decay of the $\mu$-phase and the sequential decrease in the amount of the $\sigma$-phase. 20 hours of annealing led to the formation of a double-phased state with the main $\varepsilon$-phase, however the microhardness in this case was significantly higher, than in the as-produced samples. This could be due to the non-uniform distribution of $\mathrm{Cr}$ and $\mathrm{Mo}$ inclusions and due to the fact, that in the as-produced samples the $\varepsilon$-phase is represented by pure Co and after 20 hours of annealing this phase is the solid solution on the basis of Co, containing $\mathrm{Cr}$ and Mo.

\section{Conclusions}

Samples of Co- 28 wt.\% Cr-6wt.\% Mo alloy were produced from powders of pure Co, Cr and Mo by LPBF. Due to the difference between melting temperatures of $\mathrm{Co}, \mathrm{Cr}$ and $\mathrm{Mo}$, inclusions of $\mathrm{Cr}$ and Mo were formed within the bulk of the samples. The as-produced samples had a non-uniform elemental composition and were represented by the main phase on the basis of pure Co. Increasing the annealing time led to sequential dissolution of un-melted $\mathrm{Cr}$ and Mo inclusions. Complete dissolution of $\mathrm{Cr}$ particles occurred after 10 hours of treatment, while complete dissolution of Mo particles did not occur after 20 hours of annealing. The microhardness changed non-linearly with increasing annealing time. This is caused by the phase transformations and diffusion processes occurring at such post-treatment. Complete dissolution of the Mo-particles could be achieved by increasing the annealing time or by varying the mode of LPBF.

Acknowledgement. The reported study was funded by RFBR and Tomsk region according to the research project № 19-48-700022.

\section{References}

1. Z. Zhang, X. Yao, P.Ge. Int. J. Mech. Sci. 166, 105230 (2020). Crossref

2. G. Baudana, S. Biamino, D. Ugues, M. Lombardi, P. Fino, M. Pavese, C. Badini. Met. Powder Rep. 71, 193 (2016). Crossref

3. L. Ardila, F. Garciandia, J. González-Díaz, P. Álvarez, A. Echeverria, M. Petite, R. Deffley, J. Ochoa. Phys. Procedia. 56, 99 (2014). Crossref

4. D. Beckers, N. Ellendt, U. Fritsching, V. Uhlenwinkel. Adv. Powder Technol. 31 (1), 300 (2020). Crossref

5. D.-R. Eo, S.-H. Park, J.-W. Cho Mater. Des. 155, 212 (2018). Crossref

6. S. Özbilen, A. Ünal, T. Sheppard. Powder Metall. 34 (1), 53 (1991). Crossref

7. Q. Bao, Y. Yang, X. Wen, L. Guo, Z. Guo. Mater. \& Design. 199, 109382 (2021). Crossref

8. G. Chen, S. Zhao, P. Tan, J. Wang, C. Xiang, H. Tang. Powder Technol. 333, 38 (2018). $\underline{\text { Crossref }}$

9. Y. Nie, J. Tang, J. Teng, X. Ye, B. Yang, J. Huang, S. Yu, Y. Li. Adv. Powder Technol. 31 (7), 2912 (2020). Crossref

10. K. Zhuravleva, S. Scudino, M.S. Khoshkhoo, A. Gebert, M. Calin, L. Schultz, J. Eckert. Adv. Eng. Mater. 15 (4), 262 (2013). $\underline{\text { Crossref }}$

11. C. Suryanarayana. Prog. Mater. Sci. 46, 1 (2001). Crossref

12. M. A. Surmeneva, A. Koptyug, D. Khrapov, Yu. F. Ivanov, T. Mishurova, S. Evsevleev, O. Prymak, K. Loza, M. Epple, G. Bruno, R. A. Surmenev. J. Mater. Process. Technol. 282, 116646 (2020). Crossref

13. M. A. Khimich, K. A. Prosolov, T. Mishurova, S. Evsevleev, X. Monforte, A.H. Teuschl, P. Slezak, E. A. Ibragimov, A.A. Saprykin, Z.G. Kovalevskaya, A.I. Dmitriev, G. Bruno, Y.P. Sharkeev. Nanomater. 11, 1159 (2021). Crossref

14. I. Polozov, V. Sufiiarov, A. Popovich, D. Masaylo, A. Grigoriev. J. Alloys and Compounds. 763, 436 (2018). Crossref

15. L. Bolzoni, T. Weissgaerber, B. Kieback, E. M. RuizNavas, E. Gordo. J. Mechan. Behav. Biomed. Mater. 20, 149 (2013). Crossref

16. G. Wang, J. Yang, X. Jiao. Mater. Sci. Eng. A. 654, 69 (2016). Crossref 
17. C.Z. Hargather, S.-L. Shang, Z.-K. Liu. Data in Brief. 20, 1537 (2018). Crossref

18. C.P. Heijwegen. Diffusion in the binary systems of molybdenum with nickel, iron and cobalt. Technische Hogeschool Eindhoven (1973). Crossref

19. M. Zhang, Y. Yang, C. Song, Y. Bai, Z. Xiao. J. Alloys and Compounds. 750, 878 (2018). Crossref

20. C. Song, M. Zhang, Y. Yanga, D. Wang, Y. Jia-kuo. Mater. Sci. Eng. A. 713, 206 (2018). Crossref

21. C. Song, H. Park, H. Seong, H.F. López. Metall. Mater. Transac. A. 37A, 3197 (2006). Crossref

22. H. F. López, A. J. Saldivar-Garcia. Metall. Mater. Transac. A. 39A, 8 (2008). Crossref

23. K. Ueki, Y. Kurihara, S. Mineta, Alfirano, K. Ueda, S. Namba, T. Yoneda, T. Narushima. Mater. Transac. 57 (12), 2048 (2016). Crossref

24. S. Kurosu, N. Nomura, A. Chiba. Mater. Transac. 47 (8), 1961 (2006). Crossref

25. A. Chiba, N. Nomura, Y. Ono. Acta Materialia. 55, 2119 (2007). Crossref

26. Y. Kajima, A. Takaichi, N. Kittikundecha, T. Nakamoto, T. Kimura, N. Nomura, A. Kawasaki, T. Hanawa, H. Takahashi, N. Wakabayashi. Mater. Sci. Eng. A. 726, 21 (2018). Crossref

27. M.A. Khimich, E.A. Ibragimov, N.A. Saprykina, Yu. P. Sharkeev, A. A. Saprykin. AIP Conf. Proc. 2310, 020144 (2020). Crossref

28. F.Z. Hassani, M. Ketabchi, S. Bruschi, A. Ghiotti. J. Mater. Sci. 51, 4495 (2016). $\underline{\text { Crossref }}$
29. M. A. Khimich, E.A. Ibragimov, V.V. Chebodaeva, A.A. Saprykin, Yu. P. Sharkeev. SSP. "Mater. Process. Technol." (2022). In press.

30. M. Béreš, C.C. Silva, P.W. C. Sarvezuk, L. Wu, L. H. M. Antunes, A. L. Jardini, A. L. M. Feitosa, J. Žilková, H. F. G. de Abreu, R. M. Filho. Mater. Sci. Eng. A. 714, 36 (2018). Crossref

31. C.P.Emerson. The Microstructureand the Electrochemical Behavior of Cobalt Chromium Molybdenum Alloys from Retrieved Hip Implants, FIU Electronic Theses and Dissertations. 2230. (2015). Crossref

32. Y. Chen, Y. Li, S. Kurosu, K. Yamanaka, N. Tang, Y. Koizumi, A. Chiba. Wear. 310, 51 (2014). Crossref

33. Y. Yamashita, Y. Li, E. Onodera, H. Matsumoto, A. Chiba. Mater. Transac. 51 (9), 1633 (2010). Crossref

34. J. B. Forsyth, L. M. d' Alte da Veiga. Acta Crystallographica. 15 (6), 543 (1962). $\underline{\text { Crossref }}$

35. S. Kurosu, H. Matsumoto, A. Chiba. Metall. Mater. Transac. A. 41A, 2613 (2010). Crossref

36. D.S. Bloom, J.W. Putman, N. J. Grant. J. Met. 4, 626 (1952). Crossref

37. E. N. Akhmedov. Physica B: Cond. Matter J. 571, 252 (2019). Crossref

38. W. Wang, F. Yin, M. Zhang, M. Zhao, Z. Li. JPEDAV. 35, 544 (2014). Crossref

39. S. Parshorov, R. Lazarova. J. Mater. Sci. Technol. 22 (3), 183 (2014).

40. Y. Zhang, X. Jiang, H. Sun, Z. Shao. Nanotechnol. Reviews. 9, 580 (2020). $\underline{\text { Crossref }}$ 